\title{
Identifikasi Tumbuhan Paku di Hutan Penggaron Kecamatan Ungaran Kabupaten Semarang
}

\author{
Auliya Saadatul Abadiyah¹, Baiq Farhatul Wahidah², Anif Rizqianti Hariz ${ }^{1}$ \\ ${ }^{1}$ Prodi Pendidikan Biologi UIN Walisongo Semarang \\ ${ }^{2}$ Prodi Biologi UIN Walisongo Semarang \\ Jl.Prof. Dr. Hamka Kampus 2 Ngaliyan Semarang 0185 (024)76433366 \\ *Email:auliyasa31@gmail.com
}

\begin{abstract}
Indonesia has a strategic geographical area with high biodiversity potential, it is located in the equatorial region which causes Indonesia have a tropical climate. The biodiversity of forests in Indonesia includes ferns. Nail plants can be found with a variety of types in various environments, especially in shady areas such as forests. Ferns are plants that have an important role in the forest ecosystem as a source of germplasm. Besides that, ferns also have the potential as a source of food and medicine for the Penggaron Forest, or who is familiarly called the Penggaron Tourism Area, is one of the natural tourism objects located in Semarang Regency, precisely in Susukan Village, Ungaran District, Semarang Regency. This study aims to identify the species of ferns in the Penggaron Forest. Data collection techniques used in identifying plant ferns are: 1) orientation and exploration of locations; 2) gathering ferns by exploring along the main road to the location of the campsite; 3) record and document the ferns found in the field. The results of the identification of ferns in the Penggaron Forest there are 2 families of ferns consisting of 23 species of plants. The Scizaeaceae family consists of 4 types of plants namely Lygodium flexuosum, Lygodium japonicum, Lygodium palmatum, and Lygodium circinatum. While the Polypodiaceae family consists of 19 types namely Nephrolepis hirsutula, Nephrolepis biserrata, Dryopteris scotii, Adiantum, Adiantum raddianum, Mickelopteris cordata, Pteris ensiformis, Pteris asperula, Pteris biaurita, Pteris vittata, Adiantum, Adiantum raddianum, Mickelopteris cordata, Pteris ensiformis, Pteris asperula, Pteris biaurita, Pteris vittata, Adiantum, Adiantum raddianum, Mickelopteris cordata, Pteris ensiformis, Pteris asperula, Pteris biaurita, Pteris vittata crenata, Tectaria angulata, Tectaria maingayi, Tectaria heracleifolia, Pleocnemiairregularis.
\end{abstract}

Key words: fern, identification, Penggaron Forest.

\section{Pendahuluan}

Indonesia memiliki wilayah geografis yang strategis dengan potensi keanekaragaman hayati yang tinggi, karena terletak di wilayah garis equator yang menyebabkan Indonesia memilikiiklim tropik. Keanekaragaman hayati yang dimiliki hutan di Indonesia ini antara lain tumbuhan paku. Tumbuhan paku dapat ditemukan dengan jenis yang beraneka ragam di berbagai lingkungan utamanya di daerah yang teduh sepertihutan.

Tumbuhan paku merupakan tumbuhan yang memiliki peranan penting dalam ekosistem hutan sebagai sumber plasma nutfah. Selain itu tumbuhan paku juga berpotensi sebagai sumber makanan dan obat- obatan (Suraida, 2013).

Tumbuhan paku memiliki keragaman jenis yang tinggi dan dapat hidup dalam lingkungan yang bervariasi. Penelitian mengenai tumbuhan paku belum pernah dilakukan sebelumnya di kawasan Hutan Penggaron.

Hutan Penggaron atau yang akrab disapa dengan Wana Wisata Penggaron merupakan salah satu objek wisata alam yang terletak di Kabupaten Semarang tepatnya di Desa Susukan, Kecamatan Ungaran, Kabupaten Semarang. Wana Wisata Penggaron dikola oleh Kesatuan Bisnis Mandiri Wisata Benih dan Usaha Lain (KBM WBU I) Perum Perhutani Unit 1 Jawa Tengah. Wana Wisata ini sering 
dimanfaatkanolehmasyarakatsekitaruntukber bagai aktivitas seperti olahraga, jungle, tracking, pramuka, outbond, penelitian, dan kepentingan lainnya. Lokasi Wana Wisata Penggaron dibagi menjadi beberapa lokasi yaitu gardu pandang, bumi perkemahan, dan driving range (Widiawati, 2015).

Kawasan Wana Wisata Penggaron memiliki luas mencapai 500 ha dan terletak pada ketinggian 100-350 mdpl. Kawasan ini dibagi menjadi 3 zona berdasarkan tingkat kelerengannya, yaitu zona $1(0-8 \%)$, zona II (8$13 \%$ ) dan zona III (>13\%). Potensi Wana Wisata Penggaron sebagai lokasi wisata alam sangat memadahi karena mampu memfasilitasi serangkaian jenis aktivitas masyarakat mulai dari berkemah, pendidikan lingkungan dan penelitian.

Penelitian ini bertujuan untuk mengetahui identifikasi tumbuhan paku yang ada di Hutan Penggaron, kecamatan Ungaran, kabupatenSemarang.

\section{Metode}

Metode penelitian yang digunakan adalah metode penelitian kualitatif melalui kegiatan eksplorasi tumbuhan paku di kawasan Hutan Penggaron. Pengumpulan data dilakukan dengan cara mengumpulkan berbagai jenis tumbuhan paku yang ada dikawasan kawasan Hutan Penggaron, kemudian diidentifikasi berupa klasifikasi tumbuhan, habitus, ciri dan morfologi daun (bentuk, warna, tepi), morfologi batang (bentuk, warna), letak sorus, lokasi tempat tumbuh. Identifikasi paku dilakukan denganmenggunakan buku yaitu buku morfologi tumbuhan karangan Tjitrosoepomo dan karangan Steenis, Ensiklopedia tumbuhan paku, dan website resmi www.gbif.org,www.plantamor.com, dan https://rbg-web2.rbge.org.uk/.

Pengambilan data dilakukan pada 13 Februari -13 Maret 2019 di HutanPenggaron, desa Susukan, kecamatan Ungaran, kabupatenSemarang.

Pengambilan sampel tumbuhan paku dilakukan dengan cara jelajah yaitu menjelajahi setiap lokasi yang berada dikawasan Hutan Penggaron kemudian setiap jenis tumbuhan paku yang ditemukan diidentifikasi. Teknik pengumpulan data yang dilakukan dalam identifikasi tumbuhan paku yaitu: 1) orientasi dan penjelajahan lokasi; 2) pengumpulan tumbuhan paku dengan menjelajah sepanjang jalan utama sampai lokasi bumi perkemahan; 3) mencatat dan mendokumentasikan tumbuhan paku yang ditemukan di lapangan.

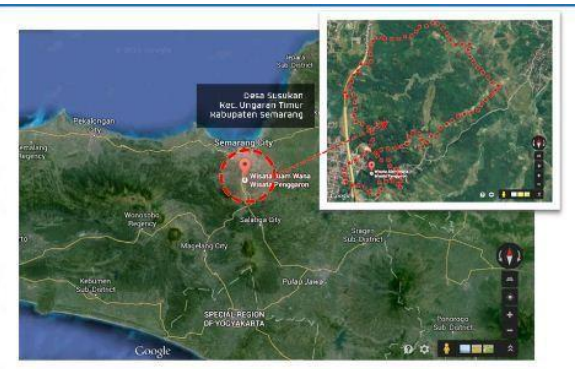

Gambar 1 Peta Lokasi Hutan Penggaron

\section{Hasil dan Pembahasan}

Hasil penelitian di $\begin{array}{r}\text { Wana Wisata } \\ \text { menunjukkan }\end{array}$
Penggaron
bahwaditemukan23 spesies tumbuhan paku
(Pteridophyta).Data diperoleh dimulai dari
jalur gerbang utama Wana Wisata Penggaron
sampai lokasi Bumi Perkemahan. Wilayah
driving range tidak dijelajahi dikarenakan
medan perjalanan yang tidak memungkinkan
untuk dilalui oleh penulis. Data 23 spesies
tumbuhan paku tersebut selengkapnya akan
disajikan pada Tabel 1.

Hasil penelitian yang dilakukan menunjukkan 23 jenis tumbuhan yang didapatkan termasuk dalam 2 famili yaitu Schizaeaceae dan Polypodiaceae. Empat jenis masuk dalam famili Scizaeaceae dan 19 jenis termasuk dalam familiPolypodiaceae.

Pteridophyta yang ditemukan di Wana Wisata Penggaron menunjukkan habitat tumbuh bagi jenis tumbuhan paku tertentu. Sebagian besar jenis paku yang ditemukan hidup di wilayah yang ternaungi oleh pohonpohon besar, sesuai dengan karakteristik 
tumbuhan paku pada umumnya yaitu hidup ditempat yang teduh.

Tabel 1. Data Tumbuhan Paku di Wana Wisata Penggaron

\begin{tabular}{cll}
\hline No & \multicolumn{1}{c}{$\begin{array}{c}\text { Nama Tumbuhan } \\
\text { (Spesies) }\end{array}$} & \multicolumn{1}{c}{ Famili } \\
\hline 1 & Lygodium flexuosum & Schizaeaceae \\
2 & Lygodium japonicum & Schizaeaceae \\
3 & Lygodium palmatum & Schizaeaceae \\
4 & Lygodium circinatum & Schizaeaceae \\
5 & Nephrolepis hirsutula & Polypodiaceae \\
6 & Nephrolepis biserrata & Polypodiaceae \\
7 & Dryopteris scotii & Polypodiaceae \\
8 & Adiantum philippense & Polypodiaceae \\
9 & Adiantum raddianum & Polypodiaceae \\
10 & Mickelopteris cordata & Polypodiaceae \\
11 & Pteris asperula & Polypodiaceae \\
12 & Pteris ensiformis & Polypodiaceae \\
13 & Pteris biaurita & Polypodiaceae \\
14 & Pteris vittata & Polypodiaceae \\
15 & Drynaria quercifolia & Polypodiaceae \\
16 & Platycerium bifurcatum & Polypodiaceae \\
17 & Microsorum scolopendria & Polypodiaceae \\
18 & Vittaria elongata & Polypodiaceae \\
19 & Tectaria crenata & Polypodiaceae \\
20 & Tectaria angulata & Polypodiaceae \\
21 & Tectaria maingayi & Polypodiaceae \\
22 & Tectaria heracleifolia & Polypodiaceae \\
23 & Pleocnemia irregularis & Polypodiaceae \\
\hline & & \\
& & \\
& & \\
& & \\
& & \\
&
\end{tabular}

Lygodium flexuosum dengan nama daerah paku kembang merupakan tumbuhan terestrial yang menjalar, memanjat ke tumbuhan yang tegak. Struktur daun sejajar antara daun sebelah kanan dan sebelah kiri. Setiap sisi cabang memiliki 3-4 anak daun. Bentuk pina memanjang, memiliki ujung yang meruncing, pangkal membulat, dan bagian tepinya bergerigi. Spora terletak di setiap bagian tepi daun. Warna batang hijau kecoklatan dengan cara tumbuh melilit dari bagian kiri (Tjitrosoepomo, 2009).

Lygodium japonicum atau dikenal dengan paku kapai besar, merupakan tumbuhan terestrial merambat. Daun majemuk rangkap dua berwarna hijau cerah dengan pangkal membulat dan ujung yang lancip, tepi daun bergerigi berwarna kecoklatan karena adanya lobus yang terdapat beberapa pasang sporangium. Batang berwarna coklat dengan percabangan dikotom (Tjitrosoepomo,2009).

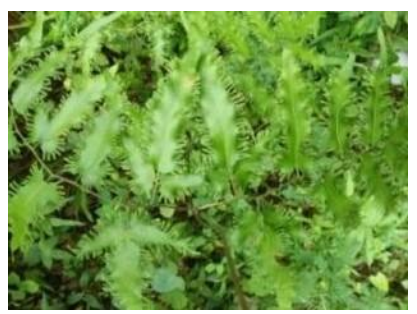

Gambar 1 Lygodium flexuosum Sumber : Dokumen Pribadi, 2019

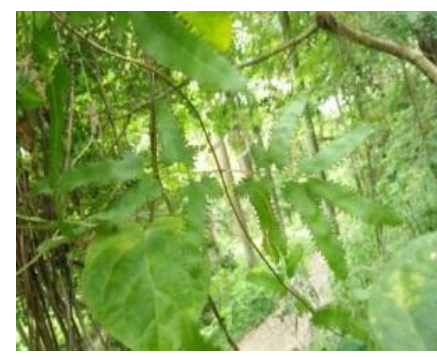

Gambar 2 Lygodium japonicum

Sumber : Dokumen Pribadi, 2019

Lygodium palmatum atau dikenal dengan nama american climbing fern merupakan kelompok paku yang merambat dan hidup di tempat yang terbuka. Daunberwarna hijau menjari, ujung runcing dan tepi rata. Batang tipis berwarna coklat dengan percabangan dikotom. Setiap sisi cabang memiliki 2 anak daun (Tjitrosoepomo,2009).

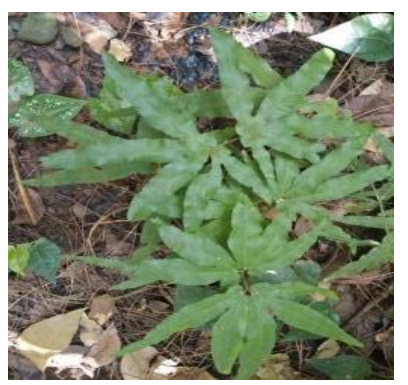

Gambar 3 Lygodium palmatum

Sumber : Dokumen Pribadi, 2019

Lygodium longifolium (paku hata)merupakan paku terestrial yang hidup 
ditempat terbuka dengan daun majemuk bangun kaki berwarna hijau tua berebentuk lanset, bertepi rata, pangkal tumpul, ujung meruncing. Batang tipis berwarna coklat dengan percabangan dikotom dan tumbuh melilit pada tumbuhan lain (Tjitrosoepomo, 2009).

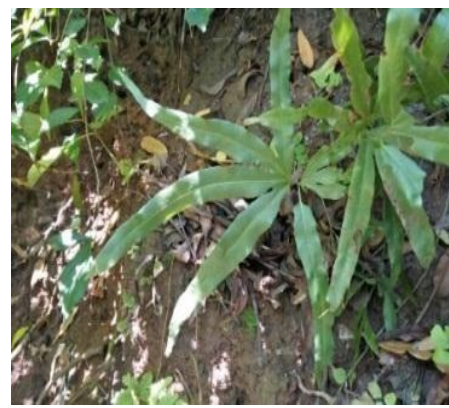

Gambar 4 Lygodiumlongifolium

Sumber : Dokumen Pribadi,2019

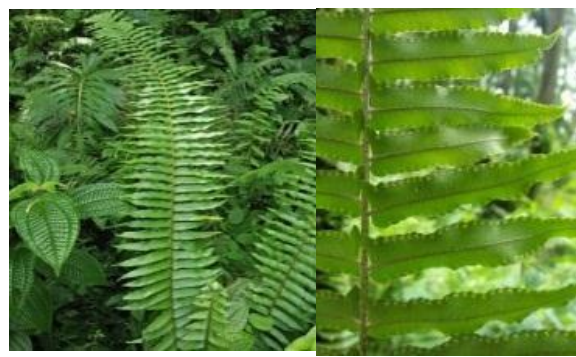

Gambar 5 Neprolepis hirsutula

Sumber : Dokumen Pribadi, 2019

Nephrolepis hirsutula atau dikenal dengan nama paku kinca merupakan tumbuhan terestrial yang banyak ditemukan di tempat yang perdu seperti dibawah pohon- pohon besar. Bentuk batang tegak berwarna hijau tua dan bersisik ketika masih muda dan berwarna kecoklatan ketika sudah tua. Tumbuhan ini berdaun majemuk dan memiliki daun hijau lanset dengan tepi lurus dan ujung lancip. Kedudukan anak daun berselang-seling saling berhadapan dengantangkai daun rapat. Permukaan daun halus dengan sorus terletak di tepi bagian atas daun (Tjitrosoepomo, 2009).

Nephrolepis biserrata atau dikenal dengan paku harupat atau paku uban. Paku ini merupakan paku terestrial yang hidup ditempat terbuka. Daun majemuk berwarna hijau muda dengan anak daun berbentuk lanset, tepi daun rata, ujung daun runcing, pangkal membulat dengan sorus tersususn rapi satu baris di tepi bawah daun. Batang bulat tegak berwarna coklat. Dryopteris scotii, merupakan tumbuhan paku terestrial hidup di tempat yang teduh. Daun majemuk lanset, tepi beringgit, ujung runcing, pangkal membulat berwarna hijau. Semakin keatas dan kebawah, anak daun semakinberukuranpendek. Batang tegak berwarna kecoklatan (Tjitrosoepomo, 2009).

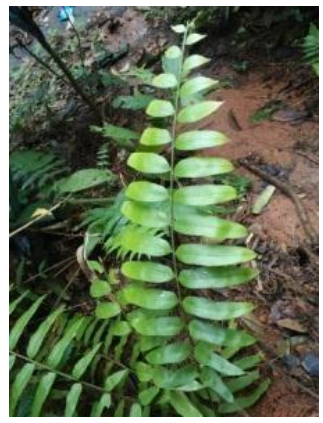

Gambar 6 Neprolepis biserrata Sumber : Dokumen Pribadi, 2019

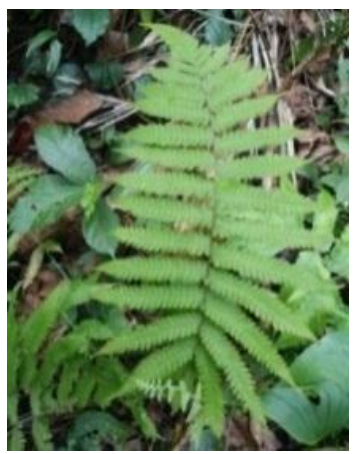

Gambar 7 Dryopteris scotii Sumber : Dokumen Pribadi, 2019

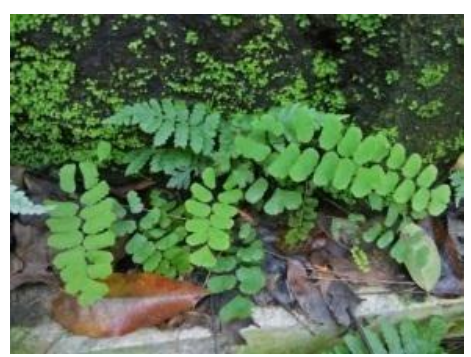

Gambar 8 Adiantumphilippense Sumber : Dokumen Pribadi,2019

Adiantum philippense atau sering disebut dengan paku suplir merupakan tumbuhan paku yang epifit dan sebagian terestrial. Daun berwarna hijau muda bentuk belah ketupat dengan sisi yang saling berhadapan, pangkal rucing dan ujung membulat. Sorus terletak di bagian tepi daun 
yang bergelombang. Batang tipis berwarna coklat dengan permukaan yang mengkilat (Tjitrosoepomo, 2009).

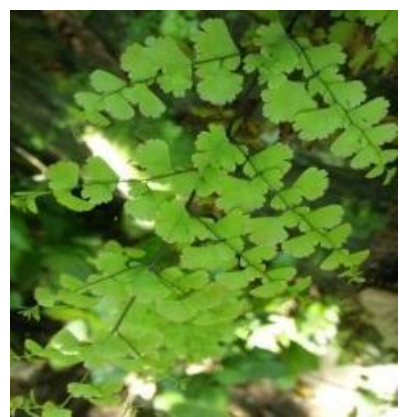

Gambar 9 Adiantumraddianum

Sumber : Dokumen Pribadi,2019

Adiantum raddianum atau sering dikenal dengan sebutan suplir melati merupakan tumbuhan paku yang berdaun majemuk dan memiliki duduk anak daun berseling. Daun berwarna hijau dengan permukaan yang licin, ujung daun membulat, pangkal tumpul, tepi daun yangberberigitdan sorus yang terletak di ujung lekukan daun. Batang berwarna coklat dengan permukaan yang licin (Tjitrosoepomo, 2009).

Mickelopteris cordata merupakan paku terestrial yang tumbuh ditengah semaksemak, daun bangun anak panah, berwarna hijau tua, tebal dengan tepi rata, ujung lancip dan pangkal berlekuk. Jika dilihat, sekilas daun M. Cordata ini lebih mirip dengan daun lompong-lompongan. Batang bulat, tegak lurus dan berwarna coklat. Spora tersebar di bawah daun (Tjitrosoepomo,2009).

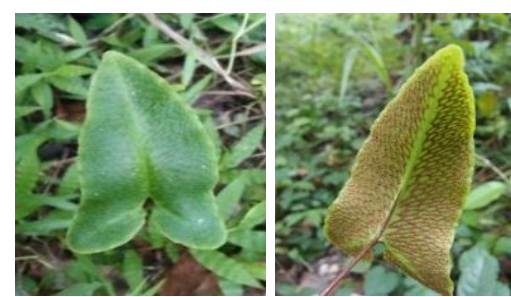

Gambar 10 Mickelopteris cordata

Sumber : Dokumen Pribadi, 2019

Pteris asperula sinonim Pteris oppositipnata merupakan paku terestrial. Daun majemuk, berwarna hijau cerah, tepi rata bercangap dengan ujung membulat dan ujung daun meruncing. Sorus terletak di bawah tepi daun berwarna coklat. Batang daun tegak lurus berwarna coklat keunguan (Tjitrosoepomo, 2009).

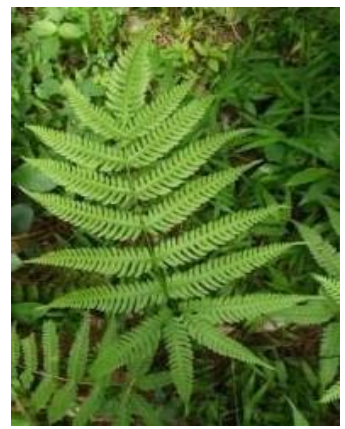

Gambar 11 Pteris asperula Sumber : Dokumen Pribadi, 2019

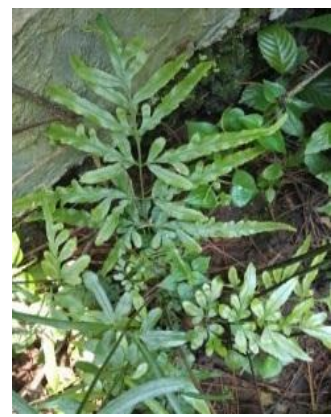

Gambar 12 Pteris ensiformis Sumber : Dokumen Pribadi, 2019

Pteris ensiformis sering dikenaldengan sebutan paku pedang atau paku pelacut merupakan paku terestrial yang memiliki dua jenis daun yaitu daun steril dan daun fertil. Daun steril memiliki tangkai yang lebih pendek dari daun fertil dan membulat dengan tepi daun yang bergerigi, anak daun dari daun fertil ini memiliki ujung yang lebih panjang dari anak daun lainnya. Sedangkan daun fertil memiliki struktur yang berbeda dengan daun steril. Daun fertil memiliki anak daun yang berbentuk taju dengan tepi yang rata. Sorus terdapat pada sepanjang tepi daun bagian bawah dan tertutup oleh tepi daun yang menggulung (Tjitrosoepomo,2009).

Pteris biaurita atu disebut dengan thinleaf rake dikelompokkan sebagai paku terestrial dengan daun majemuk berwarnahijau berbentuk lanset memanjang ujung meruncing pangkal membulat dan tepi anak daun berbentuk lonjong beroreh teratur 
dengan ujung lancip. Spora terdapat pada tepi daun memanjang mengikuti bentuk tepi daun. Batang tegak berwarna hijau muda (Tjitrosoepomo,2009).

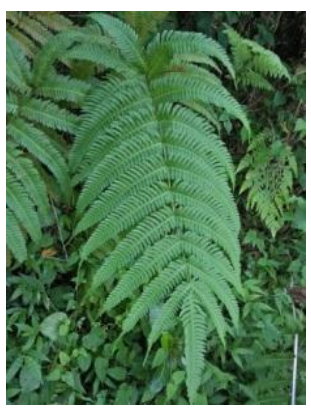

Gambar 13 Pteris biaurita Sumber : Dokumen Pribadi, 2019

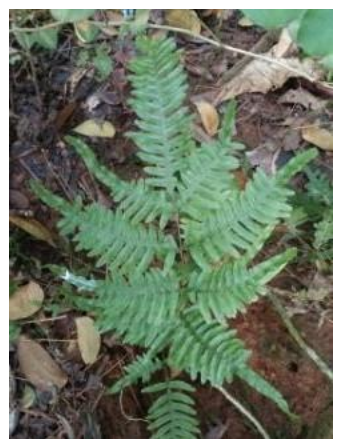

Gambar 4.14 Pteris vittata

Sumber : Dokumen Pribadi, 2019

Pteris vittata atau disebut dengan tanaman paku pakis merupakan paku terestrial dengan daun majemuk berwarna hijau berbentuk lanset ujung memanjang meruncing pangkal membulat dan tepi anak daun berbentuk lonjong bertoreh teratur dengan ujung memanjang (Tjitrosoepomo, 2009). Sorus terletak di sepanjang tepi kecuali pada ujung (Rosalin,2014).

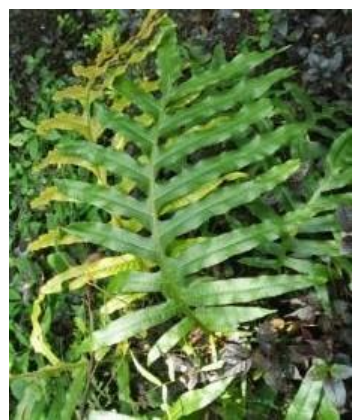

Gambar 15 Drynaria quercifolia Sumber : Dokumen Pribadi, 2019
Drynaria quercifolia dengan nama daerah paku daun kepala tupai merupakan tumbuhan paku yang bersifat epifit yangditemukan pada potongan pohon yang telah mati. Daun berwarna hijau, berbagi menyirip, ujung daun runcing, dengan permukaan yang licin dan sorus yang tersebar tidak berarturan di bawah permukaan daun bagian ujung daun (Tjitrosoepomo,2009).

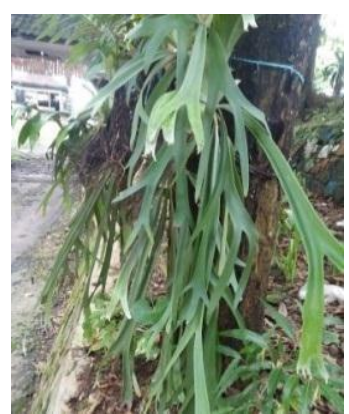

Gambar 16 Platycerium bifurcatum

Sumber : Dokumen Pribadi, 2019

Platyceriumbifurcatumsinonim

Platycerium alcicorne atau dikenal dengan sebutan paku tanduk rusa merupakan tumbuhan paku yang bersifat epifit pada pohon tanpa merugikan tumbuhan yang ditempeli. Daunnya bertipe perisai dengan struktur yang menjuntai dengan ujung yang bercabang menyerupai tanduk rusa dengan permukaan yang kasar berwarna hijau. Batang dari tumbuhan ini berbentuk rimpang (Tjitrosoepomo,2009).

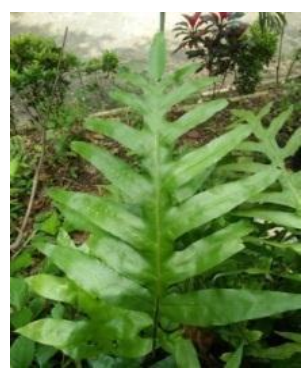

Gambar 17 Microsorum scolopendria Sumber : Dokumen Pribadi, 2019

Phymatodes scolopendria merupakan tumbuhan terestrial dan epifit dengan daun berwarna hijau mengkilat, tepi daun bertorehberbagi menyirip dan ujung tumpul. Sorus terdapat pada bagian bawah daun di bagian ujung berwarna kuning 
(Tjitrosoepomo, 2009).

Vittaria elongata atau dikenal dengan nama paku pita merupakan paku terestrial yang epifit pada pohon. Daun berwarna hijau tua dengan struktur tebal berbentuk lanset dengan tepi rata ujung dan pangkal membulat. Spora berwarna coklat tua terletak di tepi bawah permukaan ujung daun (Tjitrosoepomo,2009).

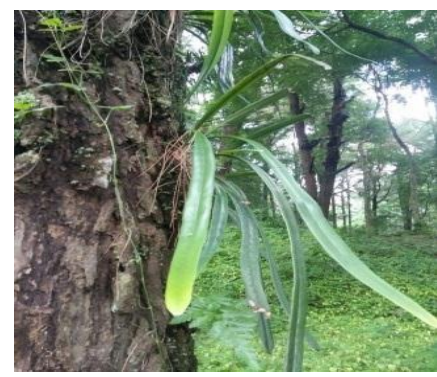

Gambar 18 Vittaria elongata

Sumber : Dokumen Pribadi, 2019

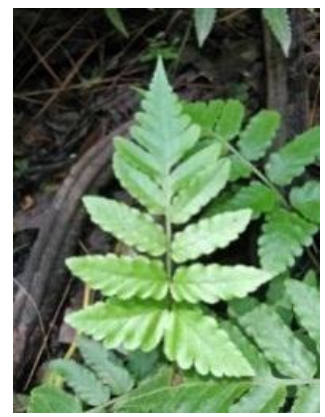

Gambar 19 Tectaria crenata

Sumber : Dokumen Pribadi, 2019

Tectaria crenata merupakan paku terestrial yang hidup ditempat yang teduh dan bergerombol dengan sesama jenisnya. Daun majemuk bertekstur kasar dan tebal dengan tepi bergerigit dan ujung lancip. Batang tegak berwarna hijau dan sorus berwarna hitam tersebar dibagian bawah daun (Tjitrosoepomo,2009).

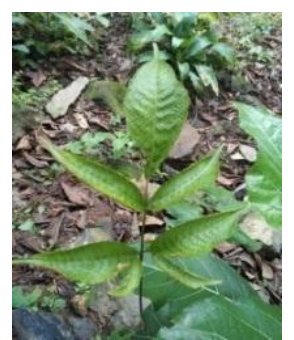

Gambar 20 Tectaria angulata

Sumber : Dokumen Pribadi, 2019
Tectaria angulata atau paku kikir merupakan paku terestrial. Daun berwarna hijau tua, tepi rata, pangkal membulat dan ujung melancip. Daun bagian atas berbentuk jorong, bagian tengah memanjang dan bagian bawah memanjang bercabang ke bawah. Daun bersifat fertil dengan spora yang tersebar diseluruh bagian bawah daun berwarna kekuningan. Batang tegak bulat berwarna coklat kehitaman (Tjitrosoepomo, 2009).
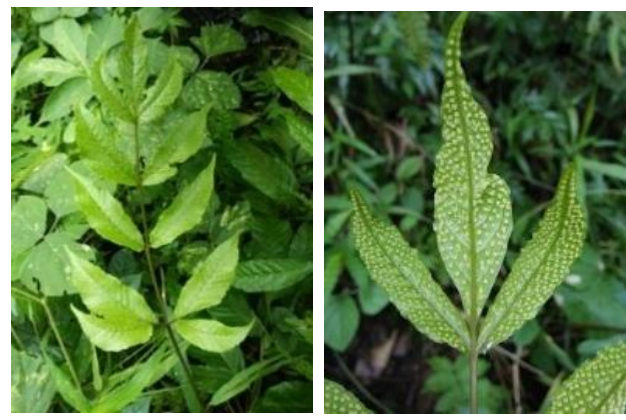

Gambar 21 Tectaria maingayi

Sumber : Dokumen Pribadi, 2019

Tectaria maingayi merupakan paku terestrial dan epifit. Daun berwarna hijau muda, tepi rata, pangkal membulat dan ujung melancip. Daun bagian atas sampai bawah berbentuk memanjang. Daun bersifat fertil dengan spora yang tersebar diseluruh bagian bawah daun berwarna kekuningan. Batang tegak bulat berwarna coklat kehitaman.Tectaria maingayi memiliki perawakan yang hampir sama dengan Tectaria angulata, perbedaannya T. Mainganyi memiliki struktur daun yang lebih ramping dan susunan anak daun lebih banyak (Tjitrosoepomo,2009).

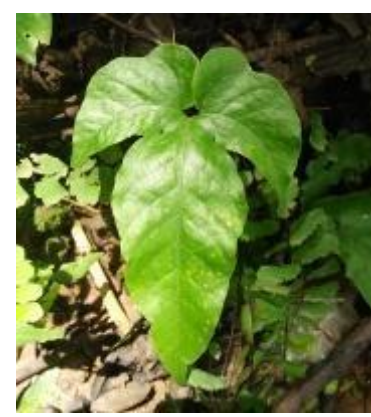

Gambar 22 Tectaria heracleifolia

Sumber : Dokumen Pribadi, 2019

merupakan paku terestrial. Daun berwarna hijau muda, tepi rata, pangkal 
membulat dan ujung melancip. Satubatang terdiri dari satu daun yang bercabang. Batang tegak bulat pendek berwarna coklat kehitaman (Tjitrosoepomo, 2009).

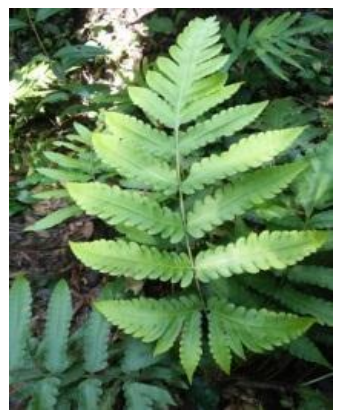

Gambar 23 Pleocnemia irregularis Sumber : Dokumen Pribadi, 2019

Pleocnemia irregularis atau dikenal dengan sebutan paku Andam merupakan paku terestrial yang hidup di tempat yang teduh. Daun majemuk memanjang, tepi beringgit, ujung runcing, pangkal membulat dan warna hijau terang. Anak daun bagian bawah bercangap menyirip dan ujungmeyatudengan bakal anak daun. Batang tegak bulat berwarna hijau (Tjitrosoepomo, 2009).

Jenis paku yang ditemukan di Hutan Penggaron diantaranya memiliki manfaat bagi manusia, diantaranya sebagai tanaman hias, obat-obatan dan bahan makanan. Tumbuhan paku yang digunakan sebagai tanamanhias diantaranya Platycerium bifurcatum atau dikenal dengan sebutan paku tanduk rusa. Selain dimanfaatkan sebagai tanaman hias, paku tanduk rusa ini juga digunakan sebagai perangkat ritual pengobatan oleh suku dayak (Fadilah dkk, 2015). Tumbuhan paku yang dimanfaatkan sebagai obat-obatan yaitu Pleocnemia Irregularis sebagai obat untuk menanggulangi diare (Novasari, 2011) dan Drynaria quercifolia yang memiliki kemampuan antihemik sebagai alternatif obat cacing Ascaridia galli (Nurhasanah,2016).

\section{Simpulan}

Identifikasi tumbuhan paku di Hutan Penggaron memperoleh hasil 2 famili tumbuhan paku yang terdiri dari 23 jenis tumbuhan. Famili Scizaeaceae terdiri dari 4 jenis tumbuhan yaitu Lygodium flexuosum, Lygodium japonicum, Lygodium palmatum, dan Lygodium circinatum. Sedangkan famili Polypodiaceae terdiri dari 19 jenis yaitu Nephrolepishirsutula,Nephrolepis biserrata, Dryopteris scotii,Adiantum,Adiantum raddianum, Mickelopteris cordata, Pteris ensiformis,Pteris asperula, Pteris biaurita, Pteris vittata, Drynaria quercifolia, Platycerium bifurcatum,Microsorum scolopendria, Vittaria elongata, Tectaria crenata, Tectaria angulata, Tectaria maingayi, Tectaria heracleifolia, Pleocnemia irregularis.

\section{Daftar Pustaka}

Fadilah, Irwan Lovadi dan Riza Linda. 2015. Pemanfaatan Tumbuhan dalam Pengobatan Tradisional Masyarakat Suku Dayak Kanayatn di Desa Ambawang Kecamatan Kubu Kabupaten Kubu Raya. Jurnal Protobiont. 4 (3) : 4959.

Novasari, Fuzzy. 2011. Karakterisasi dan Analisis Kandungan Nitrat Tanaman Pakis Sayur (Pleocnemia irregularis (C. Presl) Holttum) di Kecamatan Dramaga, Bogor. Skripsi. Bogor : Fakultas PertanianIPB.

Nurhasanah, Rian. 2016. Antihelmik Ekstrak Rimpang Paku Drynaria quercifolia terhadap Mortalitas Cacing Ascaridia galli secara in vitro. Jurnal biologi. 5 (4) :1-9.

Rosaline, Irene. 2014. Keanekaragaman Morfologi dan Struktur Reproduksi Tumbuhan Paku Terestrial di Kampus Institut Pertanian Bogor - Darmaga. Skripsi. Bogor: FMIPA IPB.

Steenis, Van. 2006. Flora: Untuk Sekolah di Indonesia. Jakarta: Pradya Paramita

Sugiyono. 2016. Metode Penelitian Pendidikan Penekatan Kualitatif, Kuantitatif dan R\&D. Bandung: Alfabeta.

Suraida, Try Susanti dan Riza Amriyanto. 2013. Keanekaragaman tumbuhan paku (pteridophyta) di taman hutan kenali kota Jambi. Prosiding Semirata FMIPA 
Unila. 387-392

Tjitrosoepomo, Gembong. 2009. Morfologi Tumbuhan. Yogyakarta: Gadjah Mada University Press.

Tjitrosoepomo, Gembong. 2009. Taksonomi Tumbuhan (Schizophyta, Thallophyta, Bryophyta, Pteridophyta). Yogyakarta: Gadjah Mada University Press.

Widiawati, Saphira. 2015. Landasan Program Perencanaan dan Perancangan Arsitektur Wana Wisata Penggaron di Kabupaten Semarang Dengan Penekanan Desain Arsitektur Tropis. Tugas Akhir. Semarang: Fakultas teknik Undip. 